\title{
A different approach for the analysis of grapes: Using the skin as sensing element
}

\author{
Raquel Muñoz ${ }^{\mathrm{a}, \mathrm{b}}$, Celia García-Hernández ${ }^{\mathrm{a}}$, Cristina Medina-Plaza ${ }^{\mathrm{a}}$, Cristina García-Cabezón ${ }^{\mathrm{a}}$, \\ J.A. Fernández-Escudero ${ }^{c}$, Enrique Barajas ${ }^{\mathrm{d}}$, Germán Medrano ${ }^{\mathrm{e}}$, María Luz Rodriguez-Méndez ${ }^{\mathrm{a}, *}$ \\ ${ }^{\text {a } G r o u p ~ o f ~ S e n s o r s ~ U V A S E N S, ~ U n i v e r s i d a d ~ d e ~ V a l l a d o l i d, ~} 47011$ Valladolid, Spain \\ • Dept. Bioquímica, Biología Molecular y Fisiología, Universidad de Valladolid, 47011 Valladolid, Spain \\ c Estación Enológica de Castilla y León, C/Santísimo Cristo, 26, 47490 Rueda, Valladolid, Spain \\ d ITACYL Avenida de Burgos, KM.118, Finca Zamadueñas, 47071 Valladolid, Spain \\ e R\&D Dept. Bodega Cooperativa de Cigales, C/Las Bodegas, s/n, 47270 Cigales, Valladolid, Spain
}

\section{A R T I C L E I N F O}

\section{Keywords:}

Phenolic maturity

Grape

Voltammetric sensor

Skin-sensor

TPI

Multisensor systems

\begin{abstract}
A B S T R A C T
In this work, an alternative method to monitor the phenolic maturity of grapes was developed. In this approach, the skins of grapes were used to cover the surface of carbon paste electrodes and the voltammetric signals obtained with the skin-modified sensors were used to obtain information about the phenolic content of the skins. These sensors could easily detect differences in the phenolic composition of different Spanish varieties of grapes (Mencía, Prieto Picudo and Juan García). Moreover, sensors were able to monitor changes in the phenolic content throughout the ripening process from véraison until harvest.

Using PLS-1 (Partial Least Squares), correlations were established between the voltammetric signals registered with the skin-modified sensors and the phenolic content measured by classical methods (Glories or Total Polyphenol Index). PLS-1 models provided additional information about Brix degree, density or sugar content, which usually used to establish the harvesting date. The quality of the correlations was influenced by the maturation process and the structural and mechanical skin properties. Thus the skin sensors fabricated with Juan García and Prieto Picudo grapes (that showed faster polyphenolic maturation and a higher amount of extractable polyphenols than Mencía), showed good correlations and therefore could be used to monitor the ripening.
\end{abstract}

\section{Introduction}

Harvesting grapes in the optimal point of maturity is a main concern for winemakers (Jackson, 2014). It is therefore important to develop chemical markers to define the optimal ripeness. The physicochemical and biochemical processes occurring during ripening process, produce a continuous rising of the sugars concentration and a decrease in the acid levels. For this reason, the classical parameters measured to monitor grape ripeness and to determine the harvesting date are the berry weight, the must density and the relation between sugars content and total acidity (Robredo, Junquera, González San José, \& Barren, 1991) in musts.

To elaborate a high quality red wine, grapes need to reach an appropriate phenolic maturation. To elaborate a high quality red wine, grapes must reach an appropriate phenolic maturation. According to the literature, phenols accumulate in the berries during ripening.
Therefore, an increase in the total phenolic content is a good indicator of the grape maturity (González-San José, Barren, \& Díez, 1990; González-San José, Barren, Junquera, \& Robredo, 1991; Mahmood, Anwar, Abbas, \& Saari, 2012).

The phenolic maturity has been measured using different methods and TPI is one possible approach (Adams, 2006; Garrido \& Borges, 2013; Kennedy, 2008; Nogales-Bueno et al., 2017).

In spite of the variety of methods mentioned, the assessment of the grape maturity is difficult task because each parameter changes with ripeness in a different manner (since they depend on different biochemical pathways). Moreover, the optimal maturity values at harvest depend on the variety of grape, the type of wine being made, weather or seasonal factors, or viticultural practices among many other factors (Lohitnavy, Bastian, \& Collins, 2010). Another difficulty is that the active metabolism of the skin during grape development has an essential effect on the final quality of the grape berries and wine (Negri

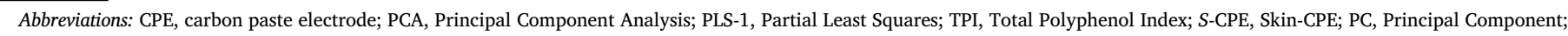
PLS-DA, Partial Least Squares Discriminant Analysis

* Corresponding author at: Dpt. Inorganic Chemistry, Escuela de Ingenierías Industriales, Paseo del Cauce, 59, 47011 Valladolid, Spain.

E-mail address: mluz@eii.uva.es (M.L. Rodriguez-Méndez). 
Table 1

Results of the chemical analysis carried out by traditional chemical methods.

\begin{tabular}{|c|c|c|c|c|c|c|c|c|c|}
\hline Sample & Week & $\begin{array}{l}\text { Glories } \\
\text { pH } 3\end{array}$ & $\begin{array}{l}\text { Glories } \\
\text { pH } 1\end{array}$ & TPI & ${ }^{\circ}$ Brix & $\begin{array}{l}\text { Density } \\
(\mathrm{g} / \mathrm{mL})\end{array}$ & $\begin{array}{l}\text { Sugars } \\
(\mathrm{g} / \mathrm{L})\end{array}$ & $\begin{array}{l}\text { Degree } \\
16.8\end{array}$ & $\begin{array}{l}\text { Degree } \\
17.5\end{array}$ \\
\hline \multirow[t]{5}{*}{ Mencía } & S1 & 0.255 & 0.396 & 11 & 18.71 & 1.0760 & 177.2 & 10.53 & 10.15 \\
\hline & S2 & 0.340 & 0.573 & 11 & 20.16 & 1.0822 & 193.1 & 11.47 & 11.05 \\
\hline & S3 & 0.454 & 0.579 & 11 & 21.65 & 1.0889 & 210.3 & 12.49 & 12.00 \\
\hline & S4 & 0.394 & 0.508 & 9 & 20.58 & 1.0840 & 197.7 & 11.75 & 11.30 \\
\hline & S5 & 0.244 & 0.452 & 17 & 20.99 & 1.0857 & 202.2 & 12.01 & 11.55 \\
\hline \multirow[t]{5}{*}{ Prieto Picudo } & S1 & 0.322 & 0.376 & 9 & 19.56 & 1.0795 & 186.3 & 11.07 & 10.65 \\
\hline & S2 & 0.474 & 0.586 & 9 & 20.93 & 1.0857 & 202.2 & 12.01 & 11.55 \\
\hline & S3 & 0.443 & 0.824 & 11 & 22.65 & 1.0933 & 221.7 & 13.17 & 12.70 \\
\hline & S4 & 0.357 & 0.662 & 9 & 21.05 & 1.0862 & 203.3 & 12.08 & 11.60 \\
\hline & S5 & 0.341 & 0.523 & 19 & 22.89 & 1.0943 & 224.1 & 13.31 & 12.80 \\
\hline \multirow[t]{5}{*}{ Juan García } & $\mathrm{S} 1$ & 0.361 & 0.396 & 14 & 17.30 & 1.0699 & 161.5 & 9.59 & 9.25 \\
\hline & S2 & 0.376 & 0.480 & 14 & 19.80 & 1.0809 & 189.7 & 11.27 & 10.80 \\
\hline & S3 & 0.593 & 0.609 & 18 & 21.59 & 1.0884 & 209.1 & 12.42 & 11.95 \\
\hline & S4 & 0.458 & 0.583 & 17 & 20.70 & 1.0849 & 200.0 & 11.88 & 11.45 \\
\hline & S5 & 0.316 & 0.418 & 29 & 22.18 & 1.0911 & 216.0 & 12.83 & 12.35 \\
\hline
\end{tabular}

et al., 2008; Rockenbach et al., 2011; Sokolowsky, Rosenberger, \& Fischer, 2015). In fact, the majority of the phenolic compounds present in wine are derived from skin which contains anthocyanins, flavonols and proanthocyanidins (tannins) (Jara-Palacios, Hernanz, EscuderoGilete, \& Heredia, 2014; Nogales-Bueno et al., 2017). So, methods are needed that analyze the phenolic composition of skins. Phenolic compounds are redox active compounds that can be analyzed by means of electrochemical methods (Blasco, González-Crevillén, González, \& Escarpa, 2007; Hoyos-Arbelaez, Vazquez, \& Contreras-Calderon, 2017; Kilmartin, 2013; Kirsanov, Mednova, Vietoris, Kilmartin, \& Legin, 2012; Rudnitskaya et al., 2017). For instance, using simple electrodes (graphite, platinum or ITO glass) the antioxidants present in teas (Buratti, Scampicchio, Giovanelli, \& Mannino, 2008; Piljac-Žegarac, Valek, Stipčević, \& Martínez, 2010), natural juices (Bordonaba \& Terry, 2012; Pisoschi, Cheregi, \& Danet, 2009), wines (Makhotkina \& Kilmartin, 2010), or onions (Zielinska, Wiczkowski, \& Piskula, 2008) can be analyzed.

Chemically modified electrodes can also be used for the detection of antioxidants. In such sensors, the electrode surface is covered with a sensing material that facilitates the charge-transfer reactions between the electrode and the solution (Barroso, Santos-Alvarez, Delerue-Matos, \& Oliveira, 2011; Durst, Baumner, Murray, Buck, \& Andrieux, 1997; Ziyatdinova, Kozlova, \& Budnikov, 2016). Many sensing materials have been used as chemical modifiers, for instance, carbon nanotubes, graphene, nanoparticles, porphyrins, phthalocyanines or conducting polymers among others (García-Hernández, García-Cabezón, MartínPedrosa, de Saja, \& Rodríguez-Méndez, 2016).

Electrochemical sensors can be combined to form Electronic tongues (ET) According to the IUPAC, an electronic tongue is a multisensor system, which consists of a number of low-selective sensors and crosssensitivity to different species in solution, and an appropriate method of pattern recognition and/or multivariate calibration for data processing (Rodriguez-Méndez, 2016). Such systems provide global information about complex samples. For instance, the electrochemical responses of the multisensor system, contain information not only of the electroactive components of the sample (i.e. phenols) but also, about other components such as protons, ions, etc. The responses of the sensors are analyzed using a pattern recognition software that allows discriminating samples with different characteristics. In addition, after an appropriate training, mathematical models can be built to correlate the measures carried out using the multisensor system and measures carried out by traditional chemical analysis.

Inspired by the concept of ETs, he aim of this work is to develop a new method to monitor the phenolic maturity of grapes based on Carbon Paste Electrodes (CPEs) that were modified with a piece of the skin of the corresponding grape. Three different varieties of Vitis vinifera grapes were included in this study (Mencía, Prieto Picudo and Juan García). Grape samples were collected weekly along their ripeness process, starting one week after véraison and until complete maturity. The electrochemical response of the skin-sensor ( $S$-CPE) was registered in phosphate buffer ( $\mathrm{pH} 7.0)$ using cyclic voltammetry. The discrimination capability of the electrodes and the ability to monitor the phenolic ripening, were analyzed by means of Principal Component Analysis (PCA) and Partial Least Squares (PLS-1). In addition, the electrochemical response of the electrodes was analyzed and compared with chemical data measured by classical chemical methods.

\section{Materials and methods}

\subsection{Reagents and solutions}

All reagents were of high purity and purchased from Sigma-Aldrich. Solutions were prepared using deionized water (Milli-Q, Millipore). Phosphate buffer solution $0.01 \mathrm{M}$ ( $\mathrm{pH} 7.0)$ was prepared from potassium monobasic and dibasic phosphate salts.

\subsection{Grape and must samples: selection and chemical analysis}

Samples of three different varieties of red grapes: Mencía, Prieto Picudo and Juan García were harvested in September-October 2013 in the vineyards of the Bodega Cooperativa de Cigales and of the Instituto Tecnológico Agrario de Castilla y León, both located in the Castilla y León region (Spain). 200 berries of each variety were collected on a weekly basis, starting one week after véraison until harvest (12, 20 and 26 of September, and 4, 8 of October 2013, samples numbered S1 to S5 respectively).

The polyphenolic content of the grapes was estimated using Total Polyphenol Index (TPI) measured as the Absorbance at $280 \mathrm{~nm}$ and the Glories method (Glories \& Augustin, 1993). Brix, Density, sugar content, Degree (16.8) and Degree (17.5) were analyzed following the international regulations (OIV, 2013). All chemical parameters are shown in Table 1.

\subsection{Skin-carbon paste electrodes (S-CPE)}

Carbon paste electrodes were prepared by mixing graphite powder (High purity Ultracarbon ${ }^{\circledR}$, Ultra F purity. Bay City, MI, USA) with the mineral oil Nujol (Fluka), in 1.5:1 (w/w) ratio. The obtained paste was packed in a $1 \mathrm{~mL}$ PVC (polyvinyl chloride) syringe (Yang, Denno, Pyakurel, \& Venton, 2015). A copper wire, inserted into the syringe, was used as the electrical contact. The voltammetric behavior of the carbon paste electrodes was analyzed in $0.01 \mathrm{M}$ phosphate buffer 
Table 2

Skin-CPE sensors prepared in this work.

\begin{tabular}{llll}
\hline Sampling date & Mencía & Prieto Picudo & Juan García \\
\hline September 12, 2013 & S1- $M$-CPE & S1-PP-CPE & S1-JG-CPE \\
September 20, 2013 & S2- $M$-CPE & S2-PP-CPE & S2-JG-CPE \\
September 26, 2013 & S3- $M$-CPE & S3-PP-CPE & S3-JG-CPE \\
October 4, 2013 & S4- $M$-CPE & S4-PP-CPE & S4-JG-CPE \\
October 8, 2013 & S5- $M$-CPE & S5-PP-CPE & S5-JG-CPE \\
\hline
\end{tabular}

adjusted to $\mathrm{pH}$ 7.0.

A piece from the skin of a fresh grape was carefully peeled using a cutter, placed on the surface of the CPE and fixed with a rubber O-ring. It is important to mention that the inner side of the skin was placed in contact with the carbon paste. Sensors were prepared using grapes from three different varieties that were collected periodically (S1 to S5). Sensors prepared are collected in Table 2.

In order to evaluate the repeatability and reproducibility of the method, devices were prepared using three different grapes from each bunch, choosing those grapes representative of the general ripening state of the vineyard. Moreover, three pieces of skin were cut from each grape and used to prepare electrodes. Using this method, nine electrodes ( 3 grapes $\times 3$ pieces of skin) were prepared from each type of grape.

\subsection{Electrochemical measurements}

Cyclic voltammetry was performed using a three electrode configuration, in an EG\&G PARC Model 263 potentiostat/galvanostat (Princeton Applied Research Corp., NJ, USA) controlled by the Echem software. $S$-CPEs were used as the working electrode and the counter electrode was a platinum wire. Potential values were referred to an $\mathrm{Ag}$ / $\mathrm{AgCl}$ electrode. All measurements were carried out in $20 \mathrm{ml}$ of $0.01 \mathrm{M}$ phosphate buffer adjusted to $\mathrm{pH}$ 7.0. Cyclic voltammograms were registered from -1.1 to $+1.1 \mathrm{~V}$ (the scan started at $0 \mathrm{~V}$ ) at a sweep rate of $0.1 \mathrm{~V} / \mathrm{s}$. Voltammograms shown in this work correspond to the average of nine replicas of each grape sample.

\subsection{Statistical analysis}

Principal Component Analysis (PCA) and Partial Least SquaresDiscriminant Analysis (PLS-DA), a non-supervised and supervised multivariate method respectively, were used to analyze and compare the voltammetric results of the different samples along maturation. Mathematical correlations between the signals obtained using the sensors and data obtained by classical chemical analysis were established using PLS-1 models.

In order to reduce the number of variables used in multivariate analysis, feature extraction was carried out using the kernel method to compress the information from the original signals and to extract meaningful data from the readings (Medina-Plaza et al., 2015). Using this method, voltammograms were multiplied by 10 smooth, bellshaped windowing functions defined as:

$\mathrm{K}_{\mathrm{i}}\left(\mathrm{V}_{\mathrm{j}}\right)=\frac{1}{1+\left(\frac{\mathrm{V}_{\mathrm{j}}-\mathrm{c}_{\mathrm{i}}}{\mathrm{a}_{\mathrm{i}}}\right)^{2 \mathrm{~b}_{\mathrm{i}}}}$

where $a_{i}, b_{i}$ and $c_{i}$ define the width, shape and center of the different windowing functions $\mathrm{K}_{\mathrm{i}}$. Subsequently, data were integrated with respect to voltage. Thus, each curve provided ten variables which were used as the input data source for statistical analysis. The analysis was carried out using the software Matlab v5.3 (The Mathworks Inc., Natick, MA, USA).

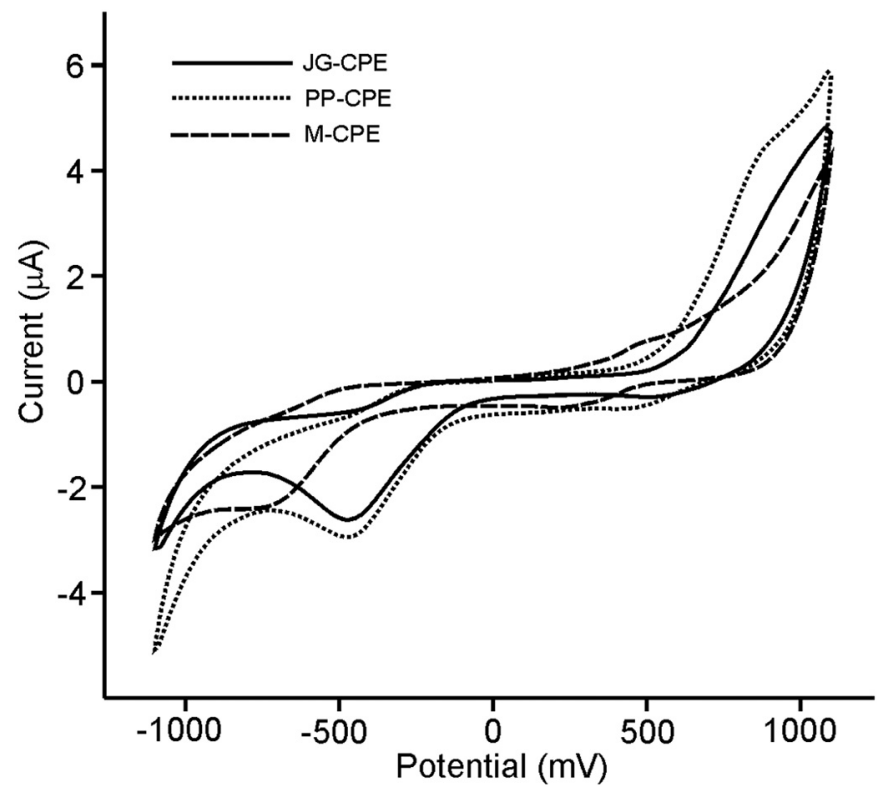

Fig. 1. Cyclic voltammetry of electrodes immersed in $0.01 \mathrm{M}$ phosphate buffer $\mathrm{pH} 7.0$. Scan rate $0.1 \mathrm{~V} / \mathrm{s}$. The grapes correspond to the second sampling on 20th September.

\section{Results and discussion}

As described in the Experimental section, a new class of sensors dedicated to the analysis of grapes was developed. Pieces of the skin grape were cut and placed on the top of the carbon surface of a CPE electrode to obtain Skin-CPE ( $S$-CPE) sensors.

The voltammetric behavior of $S$-CPE sensors modified with the skin of grapes obtained from three varieties Mencía, Prieto Picudo and Juan García (denoted as $M$-CPE, PP-CPE and JG-CPE) was tested in $0.01 \mathrm{M}$ phosphate buffer $\mathrm{pH} 7.0$ in the potential range -1.1 to $+1.1 \mathrm{~V}$. Nine replicas of each sensor were measured to study the repeatability of the voltammograms registered. Fig. 1 illustrates the electrochemical responses of $S$-CPEs modified with skins of the three varieties of grapes. In this example, grapes were collected the same day (corresponding to the second sampling collected fifteen days after véraison). Voltammograms showed an anodic wave at ca. 0.5 to $0.7 \mathrm{~V}$ and a cathodic wave in the region -0.5 to $-0.8 \mathrm{~V}$. According to the literature, these peaks can be associated to phenols present in grapes which are mainly anthocyanins and proanthocyanidins (Apetrei, Apetrei, de Saja, \& Rodriguez-Méndez, 2011; Blasco et al., 2007; Kilmartin, 2013; Makhotkina \& Kilmartin, 2013; Rodriguez-Mendez et al., 2014). Moreover, the position of redox peaks observed in diluted wines carried out using carbon electrodes, depends on the nature of the phenols present in the solution. In our case, due to the complexity of the electrode surface and the variety of phenols present on the skin, redox peaks were wider than those observed in standard aqueous solutions or in diluted wines.

$S$-CPEs prepared from different varieties of grape showed characteristic electrochemical responses, indicating that each skin grape has a specific phenolic composition which involves anthocyanin content and extractability (Rio Segade, Rolle, Gerbi, \& Orriols, 2008). Moreover, because the skin is a part of the sensitive layer, the electrochemical responses could also be influenced by structural and mechanical (porosity, hardness, thickness, etc.) properties of the skin. All these factors produced distinctive responses and justify why these $S$ CPE sensors can be used to discriminate grapes of different varieties or grapes with distinct phenolic content in its skin.

Next objective was to evaluate the capability of the $S$-CPE sensors to monitor the changes taking place during ripening. For this purpose, sensors were prepared using the skin of grapes collected during five consecutive weeks starting from véraison.

Fluctuations in the berry compositions occurring during ripening 


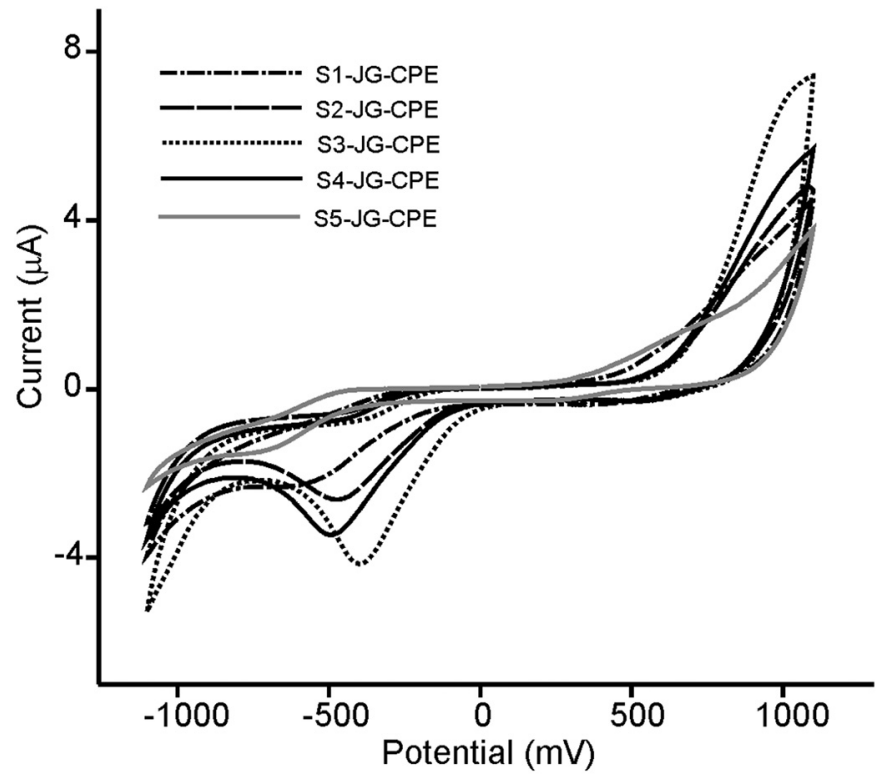

Fig. 2. Electrochemical response of $J G$-CPE electrodes along maturation. Cyclic voltammograms registered in $0.01 \mathrm{M}$ phosphate buffer $\mathrm{pH} 7.0$, Scan rate $0.1 \mathrm{~V} / \mathrm{s}$.

Table 3

Voltammetric parameters for the three skin grape-CPEs sensors: Mencía, Prieto Picudo and Juan García obtained in each sampling time.

\begin{tabular}{|l|l|l|l|l|l|l|}
\hline & \multicolumn{2}{l}{ Mencia-CPE } & \multicolumn{2}{l|}{ Prieto Picudo-CPE } & \multicolumn{2}{l|}{ Juan Garcia-CPE } \\
\hline Anodic & E $(\mathrm{mV})$ & $\operatorname{Imax}(\mu \mathrm{A})$ & $\mathrm{E}(\mathrm{mV})$ & $\operatorname{Imax}(\mu \mathrm{A})$ & $\mathrm{E}(\mathrm{mV})$ & $\operatorname{Imax}(\mu \mathrm{A})$ \\
\hline S1-S-CPE & 455 & 0.73 & 475 & 1.12 & 851 & 2.7 \\
\hline S2-S-CPE & 467 & 0.72 & 885 & 4.43 & 938 & 3.66 \\
\hline S3-S-CPE & 462 & 0.88 & 926 & 5.59 & 1030 & 7.09 \\
\hline S4-S-CPE & 744 & 1.89 & 916 & 5.50 & 1008 & 5.05 \\
\hline S5-S-CPE & 698 & 1.47 & 685 & 2.19 & 590 & 1.1 \\
\hline Cathodic & E (mV) & Imax $(\mu \mathrm{A})$ & $\mathrm{E}(\mathrm{mV})$ & $\mathrm{Imax}(\mu \mathrm{A})$ & $\mathrm{E}(\mathrm{mV})$ & $\mathrm{Imax}(\mu \mathrm{A})$ \\
peak & & & & & & \\
\hline S1-S-CPE & -706 & -1.73 & -648 & -1.87 & -581 & -2.24 \\
\hline S2-S-CPE & -731 & -2.36 & -468 & -2.94 & -468 & -2.61 \\
\hline S3-S-CPE & -693 & -1.24 & -453 & -3.15 & -395 & -4.14 \\
\hline S4-S-CPE & -726 & -2.13 & -465 & -3.14 & -493 & -3.45 \\
\hline S5-S-CPE & -699 & -1.27 & -685 & -2.19 & -694 & 1.43 \\
\hline
\end{tabular}

caused important changes in the position and intensities of the peaks (Fig. 2). The main changes corresponded to the intensity of the peaks associated to phenols that increased in intensity from véraison until a maximum was attained. Then values decreased slightly near harvesting time. This result is in good agreement with variations measured using classical chemical techniques that establish that the level of anthocyanes increases during grape ripening and decreases slightly in ripened grapes (Cadot, Chevalier, \& Barbeau, 2011; Conde et al., 2007; Liang et al., 2011; Smith, 2011). The shift of the anodic wave towards higher potentials might be a demonstration of a higher polymerization level of the skin polyphenols. This may be corroborated by the shift of the cathodic wave to less negative potentials.

The extension of the changes detected depended on the variety of grape. The voltammetric parameters obtained from the three varieties of grapes, along maturation, are summarized in Table 3 . The maximum
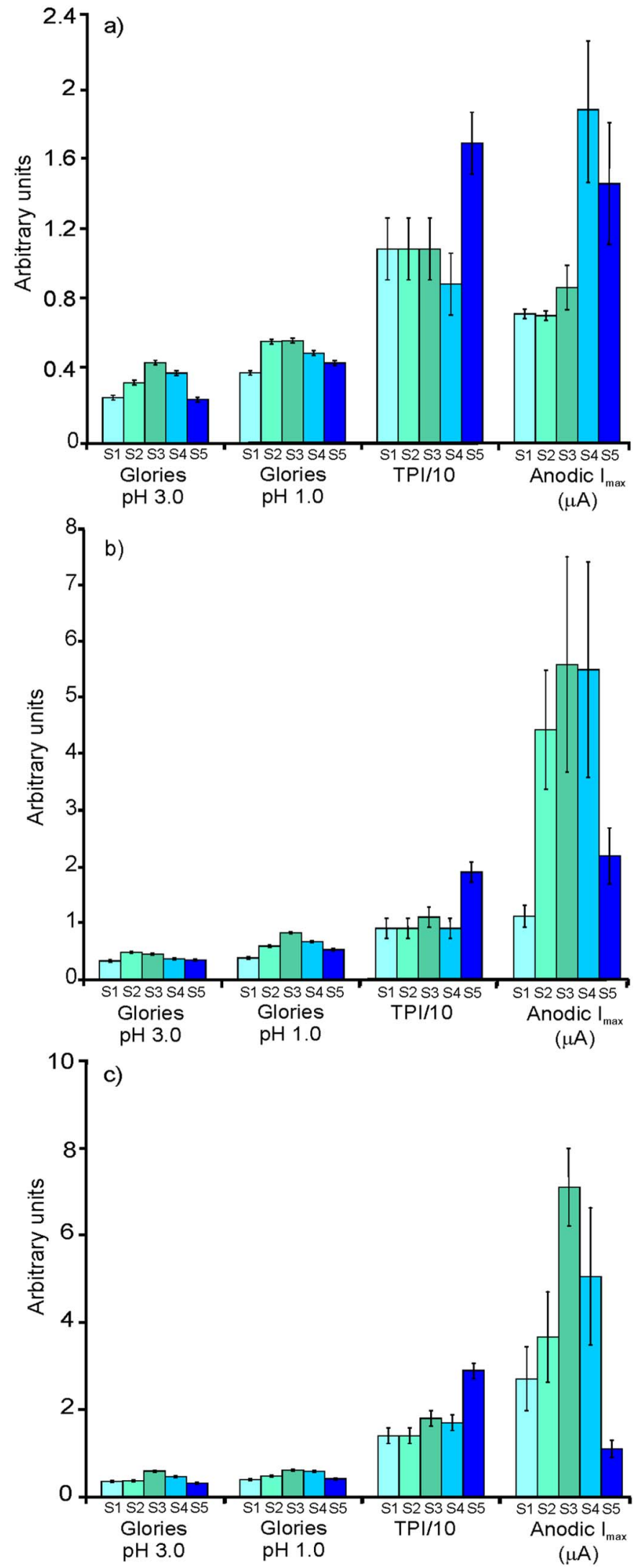

Fig. 3. Representation of the results obtained using Glories at extracts $\mathrm{pH} 3.0$ and $\mathrm{pH} 1.0$, IPT and intensity of the anodic peak for (a) $M$-CPE; (b) $P P$-CPE and (c) $J G$-CPE. 

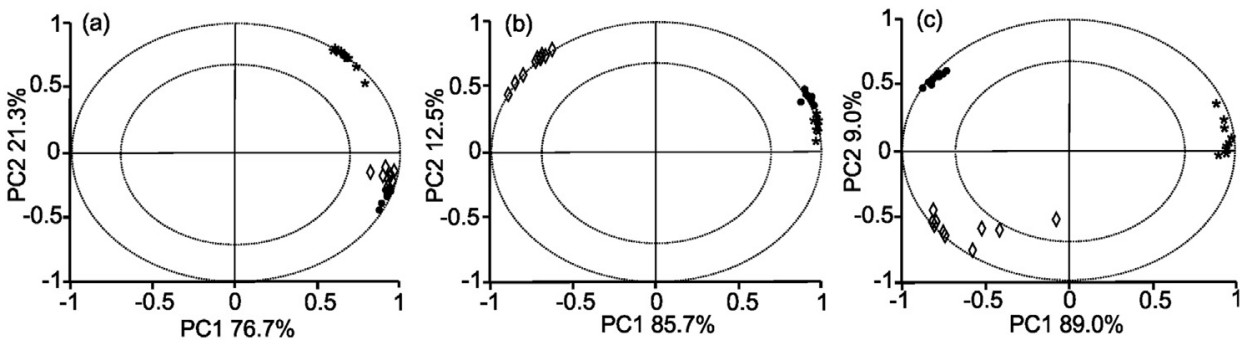

Fig. 4. Loading plot of the PCA. CPE-Mencía (๑), CPEPrieto Picudo $(\diamond)$ and CPE-Juan García (*) (ten kernels per sensor were extracted) represented at different maturation states (a) S1; (b) S3 and (c) S5.

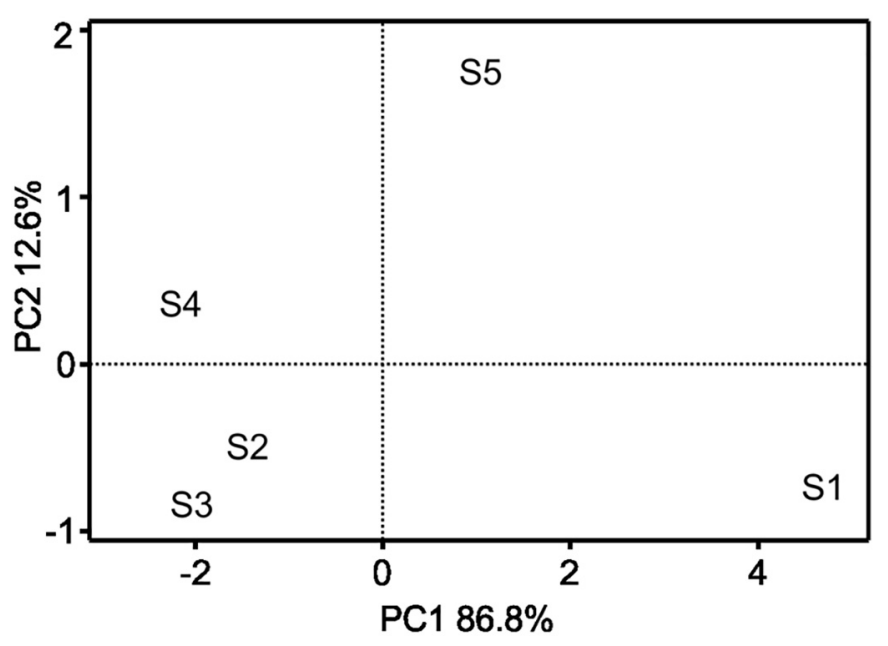

Fig. 5. Partial Least Squares Discriminant Analysis (PLS-DA) of JG-CPEs analyzed along maturation.

Table 4

Results of the PLS-1 analysis for $J G$-CPE.

\begin{tabular}{llllll}
\hline Parameter & $\mathrm{Rc}^{\mathrm{a}}$ & RMSEC $^{\mathrm{b}}$ & $\mathrm{Rp}^{\mathrm{c}}$ & RMESP $^{\mathrm{d}}$ & LV $^{\mathrm{e}}$ \\
\hline Glories pH 3 & 0.7204 & 0.0516 & 0.6718 & 0.0572 & 3 \\
Glories pH 1 & 0.7858 & 0.0397 & 0.7511 & 0.0437 & 3 \\
TPI & 0.8376 & 2.2304 & 0.8017 & 2.5207 & 3 \\
${ }^{\circ}$ Brix & 0.6967 & 0.9414 & 0.6262 & 1.0687 & 3 \\
Density (g/mL) & 0.6913 & 0.0041 & 0.6200 & 0.0047 & 3 \\
Sugars (g/L) & 0.6920 & 10.5732 & 0.6209 & 11.9976 & 3 \\
Degree (16.8) & 0.6918 & 0.6287 & 0.6205 & 0.7135 & 3 \\
Degree (17.5) & 0.6927 & 0.6023 & 0.6224 & 0.6828 & 3 \\
\hline
\end{tabular}

${ }^{\text {a }}$ Squared correlation coefficient in calibration.

${ }^{b}$ Root Mean Square Error of Calibration.

${ }^{c}$ Squared correlation coefficient in prediction.

${ }^{\mathrm{d}}$ Root Mean Square Error of Prediction.

e Latent variables.

Table 5

Results of the PLS-1 analysis for PP-CPE.

\begin{tabular}{llllll}
\hline Parameter & Rc $^{\mathrm{a}}$ & RMSEC $^{\mathrm{b}}$ & $\mathrm{Rp}^{\mathrm{c}}$ & RMESP $^{\mathrm{d}}$ & LV $^{\mathrm{e}}$ \\
\hline Glories pH 3 & 0.6177 & 0.0371 & 0.5616 & 0.0406 & 3 \\
Glories pH 1 & 0.8464 & 0.0581 & 0.8175 & 0.0648 & 3 \\
TPI & 0.6740 & 2.2142 & 0.5606 & 2.6292 & 4 \\
${ }^{\circ}$ Brix & 0.6598 & 0.7149 & 0.5632 & 0.8284 & 5 \\
Density (g/mL) & 0.6410 & 0.0033 & 0.4875 & 0.0040 & 4 \\
Sugars (g/L) & 0.6419 & 8.3456 & 0.4888 & 10.1972 & 4 \\
Degree (16.8) & 0.6416 & 0.4950 & 0.4884 & 0.6049 & 4 \\
Degree (17.5) & 0.6431 & 0.4792 & 0.4903 & 0.5857 & 4 \\
\hline
\end{tabular}

${ }^{\text {a }}$ Squared correlation coefficient in calibration.

${ }^{b}$ Root Mean Square Error of Calibration.

c Squared correlation coefficient in prediction.

${ }^{\mathrm{d}}$ Root Mean Square Error of Prediction.

e Latent variables. intensity is indicated in the table using a grey background.

The peak potentials and intensities of the anodic and cathodic waves of the three varieties of $S$-CPE sensors increased with time and decreased in the last sampling corresponding to the official date of harvest, decided by oenologists, using the Brix degree and the sugar content.

Comparing the three varieties of grapes, Mencía showed the slower polyphenolic skin maturation and the maximum redox intensity was observed in the S4 sampling. The skins of Prieto Picudo and Juan García grapes reached the maximum redox intensity in the S3 sampling, indicating a faster ripening. As shown in Fig. 3, the intensity of the redox peaks obtained from the three types of skin-based sensors along maturation, followed a similar trend than the absorbance value of grape extracts at $280 \mathrm{~nm}$ at $\mathrm{pH} 3.0$ and $\mathrm{pH} 1.0$ obtained with the Glories method, in which polyphenols are extracted from the whole grape. The advantage of the $S$-CPE sensors is that variations are more marked than in Glories and the decrease previous to maturation is easier to detect. This fact was specially observed in JG-CPE, corresponding to Juan García skin grapes, that seems to show faster polyphenolic skin maturation and a higher amount of extractable polyphenols. The variations of the Total Polyphenol Index (TPI) follow a different trend and tend to increase from véraison to complete maturity. So, TPI does not show an inflexion point that could be used to establish the optimal harvesting date. According to these results, the use of the skin of grapes as the sensitive layer provides an easy and direct method to assess the phenolic maturity of grapes.

Inspired in holistic analytical methods where arrays of sensors are combined with a pattern recognition software (Merkyte, Morozova, Boselli, \& Scampicchio, 2017; Pigani et al., 2018; Rodriguez-Méndez, de Saja, Medina-Plaza, \& Garcia-Hernandez, 2016; Sliwinska, Wisniewska, Dymerski, Namiesnik, \& Wardenci, 2014), the electroanalytical capacity of the $S$-CPE electrodes to monitor grape maturation was evaluated using Partial Least Squares-Discriminant Analysis (PLS-DA) and Principal Component Analysis (PCA).

PCA loading plot showed that $M$-CPE, $P P$-CPE and $J G$-CPE prepared in $\mathrm{S} 1$ (just one week after véraison), appeared in similar areas of the diagram (Fig. 4). Ripening caused progressive changes in the molecular and mechanical properties of skins and in their porosity. In the last sampling corresponding to mature grapes, the signals of $M$-CPE, PP-CPE and $J G$-CPE skin-based sensors appeared in different regions of the diagram, confirming that each grape possess a characteristic phenolic composition and the three varieties of grapes could be clearly discriminated.

Fig. 5 shows the Partial Least Squares-Discriminant Analysis (PLSDA) for PP-CPE samples collected along the maturation (five samplings). It was observed that the first Principal Component shifted to negative values as the ripening advanced. Then, five weeks after véraison, the PC1 returned to positive values. This circular behavior has already been observed using multisensors systems based on electrochemical electrodes (Medina-Plaza et al., 2016). PCA results found in Mencía and Prieto Picudo were similar and the clusters corresponding to the progressive maturation of grapes turned clockwise and tended to return to the initial position (data not shown).

A PLS-1 multiparametric model was established to find correlations between the results obtained with our skin sensors and the chemical 
Table 6

Results of the PLS-1 analysis for $M$-CPE.

\begin{tabular}{llllll}
\hline Parameter & $\mathrm{Rc}^{\mathrm{a}}$ & RMSEC $^{\mathrm{b}}$ & $\mathrm{Rp}^{\mathrm{c}}$ & RMESP $^{\mathrm{d}}$ & $\mathrm{LV}^{\mathrm{e}}$ \\
\hline Glories pH 3 & 0.5129 & 0.0561 & 0.2143 & 0.0728 & 10 \\
Glories pH 1 & 0.3603 & 0.0563 & 0.0336 & 0.0708 & 10 \\
TPI & 0.6916 & 1.5065 & 0.5394 & 1.8829 & 5 \\
${ }^{\circ}$ Brix & 0.3472 & 0.7962 & -0.1142 & 1.0638 & 10 \\
Density (g/mL) & 0.3379 & 0.0035 & -0.1231 & 0.0047 & 10 \\
Sugars (g/L) & 0.3386 & 8.9652 & -0.1239 & 11.9524 & 10 \\
Degree (16.8) & 0.3401 & 0.5305 & -0.1198 & 0.7067 & 10 \\
Degree (17.5) & 0.3379 & 0.5012 & -0.1257 & 0.6684 & 10 \\
\hline
\end{tabular}

a Squared correlation coefficient in calibration.

${ }^{\mathrm{b}}$ Root Mean Square Error of Calibration.

c Squared correlation coefficient in prediction.

${ }^{\mathrm{d}}$ Root Mean Square Error of Prediction.

e Latent variables.

parameters obtained by classical chemical techniques. Voltammograms can bring information not only about the polyphenolic content, but also about other components present in the skin (sugars, acids or ions) that can affect the electrochemical response. For this reason, attempts were made to use the $S$-CPEs to assess not only the phenolic content, but also to determine simultaneously other indicators of maturity.

Tables 4, 5 and 6 show the statistical parameters for the PLS- 1 regression for calibration and validation (cross-validation). The root mean square errors and the correlation coefficients at calibration (RMSEC) and prediction (RMSEP) are shown in the tables. Rc (and Rp) are correlation coefficients of calibration (and prediction). LV indicates the number of latent variables used in the calculations.

Good relationships were found between the responses provided by the $J G$-CPE (Table 4) and PP-CPE sensors (Table 5), and the phenolic content measured by Glories and TPI. Higher correlation coefficients were found with Glories at $\mathrm{pH} 1.0$ than at $\mathrm{pH}$ 3.0. The extracts at $\mathrm{pH} 1.0$ take account of the total extractable polyphenols, whereas at $\mathrm{pH} 3.0$ only easily extractable polyphenols are measured. Phenolic extractability depends of their cellular localization and degree of polymerization (Gagné, Saucier, \& Gény, 2006). These data indicate that $J G$ $\mathrm{CPE}$ and PP-CPE sensors can detect most of the polyphenolic content of the skin. In the case of TPI, correlations coefficients were not so high because this method has interferences from non-phenolic compounds that contain aromatic rings (nucleotides, aromatic amino acids, peptides or proteins). Moreover, because the whole voltammograms was used to build the mathematical model, electrochemical data bring information not only about phenols but also about other components of the skin. For this reason, good correlations were also found with other parameters of interest in oenology including sugar, degree brix, grade and density.

However, low correlations were found using the $M$-CPE (Table 6). This lack of correlation might be attributed to the delay in the phenolic maturation process of Mencía grapes and to the different properties of their skins. In addition, it is known that the porosity and the structural properties, such as number of cell layers from cuticle to flesh, and mechanical properties of the skins, such as hardness, vary from one variety of grape to another and are also influenced by environmental factors (Rolle, Gerbi, Schneider, Spanna, \& Río Segade, 2011). The evolution of skin hardness during the ripening period is not completely known, although it considered an adequate parameter for the estimation of the extractability of phenol compounds (Rolle et al., 2011). An important observation in our study is the higher difficulty to separate skin and flesh in Mencía grapes. In this sense, the degree of adhesion between skin and flesh, along ripening, was more variable in this variety that for Juan García and Prieto Picudo, varieties where the skin and flesh were properly separated in every sampling. For instance in sampling S3, Mencía grapes were collected after a heavy rain, and skin and flesh could hardly be separated. These facts might have interfered in the permeability of the skin and in consequence with the diffusion of ions and electron transfer from the skin to the electrode.

\section{Conclusions}

Skin-CPE electrodes fabricated by covering a carbon electrode with the skin of grapes can be used to evaluate the phenolic content of grapes. The redox processes at electrode surface, provided information about phenolic compounds present in the skin. The electrochemical response of the three different skin-sensors electrodes along the maturation, could be used to monitor the ripening process. Good correlations were found with other parameters suh as sugar content or ${ }^{\circ}$ Brix usually used to establish the optimal maturity. The phenolic maturation process of the vintage and the structural and mechanical skin grape properties, are esential factors, to found good correlations between the responses provided by $S$-CPE sensors and chemical data measured by classical chemical methods. Thus the skin sensors fabricated with Juan García and Prieto Picudo grapes, that showed a faster polyphenolic skin maturation and a higher amount of extractable polyphenols than Mencía variety, showed a very good correlations and therefore could be used to monitor the ripening of Juan García and Prieto Picudo grapes. Althought the presented work brings a new and original approach to monitor the phenolic maturity, it might be noticed that the elaboration of the sensors must be carried out very carefully when peeling off the grape skin.

\section{Acknowledgements}

Financial support from CICYT-FEDER (Grant n ${ }^{\circ}$ AGL2015-67482-R) and Junta de Castilla y León (Ref. VA011U16) is gratefully acknowledged. CGH thanks for the grant of JCYL (D-24112015-9).

In memoriam of José Antonio de Saja.

\section{Conflict of interest}

The authors report no conflict of interest.

\section{References}

Adams, D. O. (2006). Phenolics and ripening in grape berries. American Journal of Enology and Viticulture, 57, 249-256.

Apetrei, C., Apetrei, I. M., de Saja, J. A., \& Rodriguez-Méndez, M. L. (2011). Carbon paste electrodes made from different carbonaceous materials: Application in the study of antioxidants. Sensors, 11, 1328-1344.

Barroso, M. F., Santos-Alvarez, N., Delerue-Matos, C., \& Oliveira, M. B. P. P. (2011). Towards a reliable technology for antioxidant capacity and oxidative damage evaluation: Electrochemical (bio)sensors. Biosensors \& Bioelectronics, 30, 1-12.

Blasco, A. J., González-Crevillén, A. G., González, M. C., \& Escarpa, A. (2007). Direct electrochemical sensing and detection of natural antioxidants and antioxidant capacity in vitro systems. Electroanalysis, 19, 2275-2286.

Bordonaba, J. G., \& Terry, L. A. (2012). Electrochemical behaviour of polyphenol rich fruit juices using disposable screen-printed carbon electrodes: Towards a rapid sensor for antioxidant capacity and individual antioxidants. Talanta, 90, 38-45.

Buratti, S., Scampicchio, M., Giovanelli, G., \& Mannino, S. (2008). A low-cost and lowtech electrochemical flow system for the evaluation of total phenolic content and antioxidant power of tea infusions. Talanta, 75, 312-316.

Cadot, Y., Chevalier, M., \& Barbeau, G. (2011). Evolution of the localization and composition of phenolics in grape skin between veraison and maturity in relation to water availability and some climatic conditions. Journal of the Science of Food and Agriculture, 91, 1963-1976.

Conde, C., Silva, P., Fontes, N., Dias, A. C. P., Tavares, R. M., Sousa, M. J., ... Gerós, H. (2007). Biochemical changes throughout grape berry development and fruit and wine quality. Food, 1, 1-22.

Durst, R. A., Baumner, A. J., Murray, R. W., Buck, R. P., \& Andrieux, C. P. (1997). Chemically modified electrodes: Recommended terminology and definitions. Pure and Applied Chemistry, 69, 1317-1323.

Gagné, S., Saucier, C., \& Gény, L. (2006). Composition and cellular localization of tannins in Cabernet Sauvignon skins during growth. Journal of Agricultural and Food Chemistry, 54, 9465-9471.

García-Hernández, C., García-Cabezón, C., Martín-Pedrosa, F., de Saja, J. A., \& RodríguezMéndez, M. L. (2016). Layered composites of PEDOT:PSS/nanoparticles and PEDOT:PSS/phthalocyanines as electron mediators in sensors and biosensors. Belstein Journal of Nanotechnology, 7, 1948-1959.

Garrido, J., \& Borges, F. (2013). Wine and grape pholyphenols-A chemical perspective. Food Research International, 54, 1844-1858. 
Glories, Y., \& Augustin, M. (1993). Maturité phénolique du raisin, consequences technologiques: Application aux millésimes 1991 et 1992. Journée Tecnique du C.I.V.B.: Actes du Colloque Bordeaux. 56-61.

González-San José, M. L., Barren, L. J. R., \& Díez, C. (1990). Evolution of anthocyanins during maturation of Tempranillo grape cultivar (Vitis vinifera) using polynomial regression models. Journal of the Science of Food and Agriculture, 51, 337-344.

González-San José, M. L., Barren, L. J. R., Junquera, B., \& Robredo, L. M. (1991). Application of principal component analysis to ripening indices for wine grapes. Journal of Food Composition and Analysis, 4, 245-255.

Hoyos-Arbelaez, J., Vazquez, M., \& Contreras-Calderon, J. (2017). Electrochemical methods as a tool for determining the antioxidant capacity of food and beverages: A review. Food Chemistry, 221, 1371-1381.

Jackson, R. S. (2014). Wine science: Principles and applications. Amsterdam, The Netherlands: Elsevier Academic Press.

Jara-Palacios, M. J., Hernanz, D., Escudero-Gilete, M. L., \& Heredia, F. (2014). Antioxidant potential of white grape pomaces: Phenolic composition and antioxidant capacity measured by spectrophotometric and cyclic voltammetry methods. Food Research International, 66, 150-157.

Kennedy, J. A. (2008). Grape and wine phenolics: Observations and recent findings. Ciencia e Investigación Agraria, 35, 107-120.

Kilmartin, P. A. (2013). Electrochemistry applied to the analysis of wine: A mini-review. Electrochemistry Communications, 67, 39-42.

Kirsanov, D., Mednova, O., Vietoris, V., Kilmartin, P. A., \& Legin, A. (2012). Towards reliable estimation of an "electronic tongue" predictive ability from PLS regression models in wine analysis. Talanta, 90, 109-116.

Liang, Z., Sang, M., Fan, P., Wu, B., Wang, L., Duan, W., \& Li, S. (2011). Changes of polyphenols, sugars, and organic acid in 5 Vitis genotypes during berry ripening. Journal of Food Science, 76, 1750-3841.

Lohitnavy, N., Bastian, S., \& Collins, C. (2010). Berry sensory attributes correlate with compositional changes under different viticultural management of Semillon (Vitis vinifera L.). Food Quality and Preference, 21, 711-719.

Mahmood, T., Anwar, F., Abbas, M., \& Saari, N. (2012). Effect of maturity on phenolics (phenolic acids and flavonoids). Profile of strawberry cultivars and mulberry species from Pakistan. International Journal of Molecular Sciences, 13, 4591-4607.

Makhotkina, O., \& Kilmartin, P. A. (2010). The use of cyclic voltammetry for wine analysis: Determination of polyphenols and free sulfur dioxide. Analitica Chimica Acta, $668,155-165$.

Makhotkina, O., \& Kilmartin, P. A. (2013). Electrochemical oxidation of wine polyphenols in the presence of sulfur dioxide. Journal of Agricultural and Food Chemistry, 61, 5573-5581.

Medina-Plaza, C., de Saja, J. A., Fernández-Escudero, J. A., Barajas, E., Medrano, G., \& Rodriguez-Méndez, M. L. (2016). Array of biosensors for discrimination of grapes according to grape variety, vintage and ripeness. Analytica Chimica Acta, 947, 16-22.

Medina-Plaza, C., Garcia-Hernandez, C., de Saja, J., Fernández-Escudero, J. A., Barajas, E., Medrano, G., ... Rodriguez-Méndez, M. L. (2015). The advantages of disposable screen-printed biosensors in a bioelectronic tongue for the analysis of grapes. $L W T$ Food Science and Technology, 62, 940-947.

Merkyte, V., Morozova, K., Boselli, E., \& Scampicchio, M. (2017). Fast and simultaneous determination of antioxidant activity, total phenols and bitterness of red wines by a multichannel amperometric electronic tongue. Electroanalysis. Wiley Online Library.

Negri, A. S., Prinsi, B., Rossoni, M., Failla, O., Scienza, A., Cocucci, M., \& Espen, L. (2008). Proteome changes in the skin of the grape cultivar Barbera among different stages of ripening. BMC Genomics, 9, 1-19.

Nogales-Bueno, J., Baca-Bocanegra, B., Rooney, A., Hernández-Hierro, J. M., Byme, H. J., \& Heredia, F. J. (2017). Study of phenolic extractability in grape seeds by means of
ATR-FTIR and Raman spectroscopy. Food Chemistry, 232, 602-609.

OIV (2013). Compendium of international methods of analysis of wines and musts. Vol. 2 (Paris).

Pigani, L., Simone, G. V., Foca, G., Ulrici, A., Masino, F., Cubillana-Aguilera, L., ... Seeber, R. (2018). Prediction of parameters related to grape ripening by multivariate calibration of voltammetric signals acquired by an electronic tongue. Talanta, 178, 178-187.

Piljac-Žegarac, J., Valek, L., Stipčević, T., \& Martínez, S. (2010). Electrochemical determination of antioxidant capacity of fruit tea infusions. Food Chemistry, 121, $820-825$.

Pisoschi, A. M., Cheregi, M. C., \& Danet, A. F. (2009). Antioxidant capacity of some commercial fruit juices: Electrochemical and spectrophotometrical approaches. Molecules, 14, 480-493.

Rio Segade, S., Rolle, L., Gerbi, V., \& Orriols, I. (2008). Phenolic ripeness assessment of grape skin by texture analysis. Journal of Food Composition and Analysis, 21, 644-649.

Robredo, L. M., Junquera, B., González San José, M. L., \& Barren, L. J. (1991). Biochemical events during ripening of grape berries. Italian Journal of Food Science, 3 , 173-180.

Rockenbach, I. I., Valdemiro, L., Rizelio, V. M., de Souza, A. E., Genovese, M. I., \& Fett, R. (2011). Phenolic compounds and antioxidant activity of seed and skin extracts of red grape (Vitis vinifera and Vitis labrusca) pomace from Brazilian winemaking. Food Research International, 44, 897-901.

Rodriguez-Méndez, M. L. (2016). Electronic noses and tongues in the food industry. ElsevierAcademic Press.

Rodriguez-Mendez, M. L., Apetrei, C., Gay, M., Medina-Plaza, C., de Saja, J. A., Vidal, S., ... Cheynier, V. (2014). Evaluation of oxygen exposure levels and polyphenolic content of red wines using an electronic panel formed by an electronic nose and an electronic tongue. Food Chemistry, 155, 91-97.

Rodriguez-Méndez, M. L., de Saja, J. A., Medina-Plaza, C., \& Garcia-Hernandez, C. (2016). Electronic tongues for the organoleptic characterization of wines. Electronic noses and tongues in the food industry (pp. 265-273). Amsterdam, The Netherlands: Elsevier Academic Press.

Rolle, L., Gerbi, V., Schneider, A., Spanna, F., \& Río Segade, S. (2011). Varietal relationship between instrumental skin hardness and climate for grapevines (Vitis vinifera L.). Journal of Agricultural and Food Chemistry, 59, 10624-10634.

Rudnitskaya, A., Schnidtke, L. M., Reis, A., Domingues, M. R., Delgadillo, I., Debus, B., .. Legin, A. (2017). Measurements of the effects of wine maceration with oak chips using an electronic tongue. Food Chemistry, 229, 20-27.

Sliwinska, M., Wisniewska, P., Dymerski, T., Namiesnik, J., \& Wardenci, W. (2014). Food analysis using artificial senses. Journal of Agricultural and Food Chemistry, 62, 1423-1448.

Smith, C. (2011). Phenol chemistry and winemaking. Wines and Vines, 54-59 (April).

Sokolowsky, M., Rosenberger, A., \& Fischer, U. (2015). Sensory impact of skin contact on white wines characterized by descriptive analysis, time-intensity analysis and temporal dominance of sensations analysis. Food Quality and Preference, 39, 285-297.

Yang, C., Denno, M. E., Pyakurel, P., \& Venton, B. J. (2015). Recent trends in carbon nanomaterial-based electrochemical sensors for biomolecules: A review. Analitica Chimica Acta, 887, 17-37.

Zielinska, D., Wiczkowski, W., \& Piskula, M. K. (2008). Determination of the relative contribution of quercetin and its glucosides to the antioxidant capacity of onion by cyclic voltammetry and spectrophotometric methods. Journal of Agricultural and Food Chemistry, 56, 3524-3531.

Ziyatdinova, G., Kozlova, E., \& Budnikov, H. (2016). Chronocoulometry of wine on multiwalled carbon nanotube modified electrode: Antioxidant capacity assay. Food Chemistry, 196, 405-410. 